\title{
Can ICTs Contribute to the Efficiency and Provide Equitable Access to the Health Care System in Sub-Saharan Africa? The Mali Experience
}

\author{
C. O. Bagayoko $0^{a, b, c}, A$. Anne ${ }^{b, c}$, M.Fieschid ${ }^{d}$, A. Geissbuhler ${ }^{a}$ \\ a Department Radiology and Medical Informatics, University Hospitals of Geneva, Switzerland \\ ${ }^{b}$ Department of Public Health and Specialties, Medical School, University of Bamako, Mali \\ 'Centre d'Expertise et de Recherche en Télémédecine et E-santé, Hôpital Mère Enfant, Bamako, Mali \\ ' Laboratoire d'Enseignement et de Recherche sur le Traitement de l'Information Médicale, University \\ of Marseille, France
}

\begin{abstract}
Summary
Objective: The aim of this study is to demonstrate from actual projects that ICT can contribute to the balance of health systems in developing countries and to equitable access to human resources and quality health care senvice. Our study is focused on two essential elements which are: i) Capacity building and support of health professionals, especially those in isolated areas using telemedicine tools; ii) Strengthening of hospital information systems by taking advantage of full potential offered by open-source software. Methods: Our research was performed on the activities carried out in Mali and in part through the RAFT (Réseav en Afrique Francophone pour la Téémédecine) Network. We focused mainly on the activities of e-learning, telemedicine, and hospital information systems. These indude the use of platforms that work with low Internet connection bandwidth. With regard to information systems, our strategy is mainly focused on the improvement and implementation of opensource tools.

Results: Several telemedicine application projects were reviewed including continuing online medical education and the support of isolated health professionals through the usage of innovative tools. This review covers the RAFT project for continuing medical education in French-speaking Africa, the tele-radiology project in Mali, the "EQUI-ReshuS" project for equal access to health over ICT in Mali, The "Pact-e.Santé" project for community health workers in Mali.We also detailed a large-scale experience of an open-source hospital information system implemented in Mali: "Cinz@n". Conclusion: We report on successful experiences in the field of telemedicine and on the evaluation by the end-users of the Cinz@n project, a pilot hospital information system in Mali. These reflect the potential of healthcare-IC for Sub-Saharan African countries.

Keywords

Telemedicine, tele-expertise, teleradiology, ultrasonography, Africa
\end{abstract}

Yearb Med Inform 2011:33-8

\section{Introduction}

The healthcare system in sub-Saharan Africa is characterized mainly by three major problems: a) a severe shortage of health care professionals, especially in rural areas within countries, source of medical deserts, particularly in the very large countries; b) a severe imbalance in terms of healthcare services offered and professionals leading to a sharp inequality in access to care, and c) the absence of healthcare information systems, especially within care facilities.

Given all these problems it is expected that the use of information and communication technologies (ICT) will provide immediate and significant solutions to the healthcare system. This potential has been evoked in 2005 by the World Health Organization in its resolution WHA58.28 on e-health [1]. Its regional committee for Africa has reinforced this position in August 2010 by adopting a resolution in Malabo on "solutions for e-health in the African region: current state and perspective." This resolution is intended primarily to encourage African states to recognize the role of ICT in enabling the strengthening of health systems in order to accelerate the achievement of the Millennium Development Goals (MDGs).

The aim of our study is to demonstrate through tangible realizations that it is neither unrealistic nor utopian to think that the use of ICT can be a powerful vector of balance in health systems but also a way to promote equal access to care in Sub-Saharan African countries.

\section{Methodology}

Our study is based on a series of cases from the experience of ICT application in the field of health. We will focus mainly on three areas: activities of telemedicine, hospital information systems and capacity building in e-health and medical informatics. In all three cases we will be focusing on projects that have been already completed or are underway in Mali and replicated or can be reproduced in other Sub-Saharan African countries.

The specific methods and tools to each project will be describe in their review.

\section{Projects Review}

\section{eHealth and Telemedicine Activities}

Role of ICT in Continuing Medical Education in Developing Countries

Although its influence on medical practice can be discussed in certain domains [2], continuing medical education is 
necessary to provide quality healthcare. It also motivates the professional development of health care workers especially in remote areas where there are fewer peer discussion and exchange opportunities.

It is an ancient practice that dates back to the city of Venice in 1300 where the specialist certification gave the initial right to practice medicine. Introduced into Western medicine for a long time, it is required in the U.S. for nearly 40 years [3] and in France only since 2002.

It is still optional in developing countries like those in Sub-Saharan Africa where health professionals are the ones who are demanding its application.

The last twenty years have seen a surge of telemedicine platforms to support this continuing medical education $[4,5]$.

What about the Sub-Saharan countries?

According to the World Health Organization (WHO) most countries of Sub-Saharan Africa suffer from an acute crisis of qualified health professional.

In light of that reality it is difficult to think that they will have the necessary financial and organizational resources to reverse this trend quickly. It therefore becomes essential to explore the appropriateness of ICT for a wide and low-cost training.

Convinced of not having access to continuing medical education when posted in rural areas after medical school and with the advent of the Internet in 1996 in Mali, some students asked a important question at the preparatory conference of the World Information Summit in Bamako in 2000. They framed the issue as follows "We will soon graduate, we will be serving in remote areas, how we will continue to improve our skills and learn about new medical discoveries without any professional contact with our peers?" This sparked the use of ICT to support health professionals within the country, thus, the birth of the first telemedicine pilot project in Mali, led by REIMICOM (Réseau Informatique Malien d'Information et de Communication, i.e. Malian Net- work of Information and Communication) and funded by the State of Geneva, Switzerland. This project brought convincing results in Mali [6, 7] in a short period of time, and contributed to the development of a wider network for continuing medical education [8] as part of the RAFT, the network in French Speaking Africa for Telemedicine [9]. This network initially covered French-speaking countries and is now increasingly extending to English speaking ones under the auspices of WHO with currently 18 active countries in around the continent. It is also a WHO collaborating center for e-health and telemedicine [10].

In terms of results, courses of continuing medical education are offered by health professionals in Africa since 2001, on a weekly basis. Primarily targeting those working in isolated regions, they are broadcast every Thursday morning and accessible anywhere with even a low speed ( 25 to $40 \mathrm{kbits} / \mathrm{s}$ ) Internet connection. Nearly 1'500 hours of e-courses have been performed on the network to date. All courses are followed by discussions through an e-learning platform(Dud@1) which connects the speaker and participants. It is im- portant to note that $80 \%$ of these courses are now produced and webcast from Africa by African experts. Even if a study by the RAFT network had concluded that the key to the success of such practice depends more on the organizational feature than the technological aspects [11], it is clear this method of training through ICT would be a failure without concrete adaption of the necessary tools suitable to the African context. These include the distance learning platform Dud@1 which allows distributing and receiving the online courses with very low Internet speed using any computer. The overall environment is open-source and users need no additional program installation except free Java software. All existing courses are available to anyone. This system, based on a technological environment adapted to the local infrastructure, providing access to continuing education to thousands of health professionals, convincingly demonstrates the potential of ICT in medical education in low-resource countries, in particular with the development of SouthSouth collaboration network, and long-term sustainability through institutional anchoring.

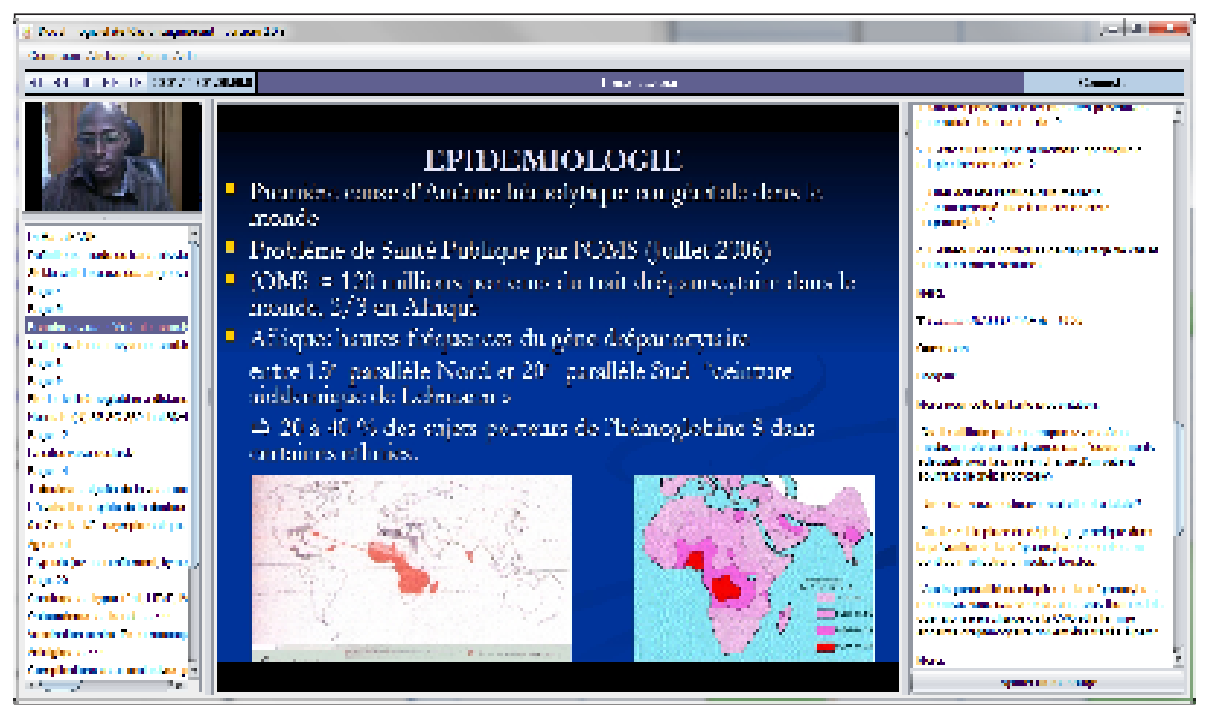

Fig.1 The Dud@l listener's interface for continuing medical education 


\section{Support Health Professionals through Innovative ICT}

The management of medical personnel is problematic in every country of the world, especially when it comes to services by specialists in remote areas. A recent law in France allowing the practice of telemedicine for remote expertise illustrates this fact [12].

This problem becomes more challenging when focusing on the health care systems in developing countries especially those in Sub-Saharan Africa. Outside their capitals, these countries face severe shortages of health professionals of all categories (nurses, midwives, general practitioners and specialists). Members of the last category (i.e. specialists) are almost exclusively concentrated in the main cities at the expense of other regions of the countries. Without a miracle solution to train in mass these specialists and deploy them in the places where there is a great need, the only credible alternative to make their expertise available all over the country is to move the expertise, rather than moving them or their patients, through the use of ICT.

To illustrate this, two projects from Mali are described here: one focusing on imaging and the other offering a service package to make the health care accessible for all:

\section{The Project of Tele-radiology IKON in Mali}

Why implement a tele-imaging network in Mali? With only a dozen radiologists providing service for 14 million inhabitants and with all of them practicing in Bamako, the capital of Mali, the answer to such question is clear and simple. Paradoxically, at least all regional hospitals in the country are equipped with radiological units with technicians capable of performing the examinations. To overcome this problem it was necessary to imagine a scenario of collaboration between regional hospitals and experts concentrated in the capital via the use of the Internet. The IKON project was initi- ated in 2005: x-ray images performed by technicians are scanned and sent to experts with information on clinical indications via a server. Every day the expert reviews all the cases and responds to requests from regional hospitals. Urgent cases that cannot wait for the regular hours for processing are communicated to the experts by phone. From its inception in 2005 until now the network links the University Hospital of Point $G$ in Mali which is the focal point of expertise for regional public hospitals as well as for a private clinic. The network currently extends to Gabon and will continue to grow within Mali and in other African countries.

To date, more than 2'500 cases have been processed, including 144 urgent cases and 103 cases for screening for breast cancer. It is estimated that these activities have saved the population a little more than 60 million CFA francs, or about 125,000 USD. This financial estimate does not include collateral expenses incurred by the patient when travelling to the capital to get medical exams done. For example the loss of earnings for a farmer forced to leave work in order to accompany his wife to the capital during the raining season can be hard to quantify.

The evaluation conducted during the five-year review of the project shows the overall satisfaction of patients in almost $98 \%$ of cases regarding the services offered. With regard to health professionals they were satisfied in all $100 \%$ of the cases.

It would be important to replicate these positive results through in-depth evaluation of a return on investment in tele- imaging to formulate great and irrefutable arguments in order to convince decision-makers. Such a study is already planned by the Center for Expertise and Research in Telemedicine and E-health.

\section{The EQUI-ResHuS Project [13]}

The main purpose of the EQUI-ResHuS project (ICT for equitable access to qualified, motivated and well supported human resources in health in French Speaking Africa) is to find out whether ICT can contribute to an equitable distribution of human resources and health care services in the countries of the scope of the study.

The project which started in December 2009 for three years will allow to better understand and objectively measure the following research questions: a) assess the role of ICT in medical education, motivation of health professionals in three pilot sites in Mali; b) experiment with the delegation of tasks in the areas of medical imaging (Obstetric ultrasound) and cardiology; c) establish a knowledge evaluation grid for implementing large-scale telemedicine tools from the results of the study on the pilot sites; d) test the role of a computer simulator in the clinical reasoning, medical decision making and teacher training in medicine; e) the impact of medical teleconsulation in caring for patient in situation of isolation; f) stimulate and develop research capacity in the field of e-health through medical graduation theses.

The main activity of this project is currently focused on the delegation of tasks in the field of medical imaging, including ultrasound imaging and telecardiology (electrocardiography).Other areas such as remote continuing medical education will be especially and properly assessed continuously during the three years of the project.

Methods for the delegation of tasks: four pilot district hospitals are equipped with internet connection, portable ultrasound and electrocardiogram which operate via USB connection to laptops. Two health professionals from the district hospital (general practitioner, midwife or nurse on duty) got previously trained by specialists in cardiology and imaging of the University Hospitals of Bamako for the manipulation and interpretation of basic tests (ultrasound imaging for obstetrics and ECG for cardiac emergencies). The goal is to enable them to diagnose early an ab- 
normal pregnancy and decide a fast support treatment by using the ultrasound images. It is the same scenario as with a congenital heart electrocardiogram (Figure 1). For complicated and difficult cases to interpret, the images are sent instantly to the Center of Expertise and Research in Telemedicine and E-health, which, thanks to its staff of medical doctors, will assign them to the available appropriate specialists, who will read them and return results to the applicants. For this purpose, 24 hours $/ 7$ services is provided at the Center of Expertise and Research in telemedicine. The training lasts 42 hours of classes and laboratory time for two weeks for the subject of ultrasound and 24 hours for a week for electrocardiography.

After training, all cases examined in remote hospitals are sent to experts via the Internet connection for at least three months, in order to verify the diagnostic ability of the trained professionals. This is done using a specifically designed platform to transmit images on low-bandwidth connections. The assessment takes into account the socio-anthropological aspects of ICT.

Results for the delegation of tasks for ECG and ultrasound imaging: in the 10 -month period deployment for the first two district hospitals and two months for the last two, respectively 453 and 73 cases of ultrasound imaging and ECG were treated by experts remotely. The cases relate mostly to pregnant women and children with congenital heart diseases. Diagnoses made by local care professionals were confirmed in $99 \%$ of cases by the experts.

Two anecdotes illustrate the impact of these tools on the satisfaction of both patients and care professionals: a patient said: "the mere fact of asking me to go to Bamako, Mali's capital for further examination is greatly exacerbated my illness. This project is a miracle for me."; a doctor said: "I refused a more interesting job because of this project."

Additionally, this project has changed the patients' perception about the health facilities. They become more comfortable with on-site diagnostic tools and appreciative of the opportunities to have remotely the advice of experts, whom they are not sure to meet easily even by bearing the cost of a trip to the capital. However, evaluations will continue throughout the project in order to get objective results on the role of these tools in the equity in access to health, their net impact on motivation and retention of health professionals in remote areas and finally the economic benefits and improved services.

\section{Telemedicine in the Peripheral Structures Closest to the People: the Case of PACT- e.Santé Project}

The PACT-e.Santé project "Programme d'Accès Communautaire à la Télémedecine et E-santé" aims to bring to the healthcare frontline the potential benefits of ICT and innovative tools. In addition to continuing medical education and tele-consultation, we have developed tele-cytology activities using cheaper innovative tools such as a cheap, portable digital microscope.

To date 26 community health centers benefit from this project which was initiated in 2009. The goal is to demonstrate improvements in the quality of patient care services in the firstline of healthcare. Ultimately, this should lead to a reduction of the current bottleneck at the few major hospitals which are often overwhelmed with cases that could be taken care of at the primary and secondary levels, while the centers closest to the populations remain underutilized due to lack of patient confidence.

\section{Conclusion}

After ten years of practice of eHealth and telemedicine activities in French Speaking Africa, mainly continuing medical education, tele-consultation and recently the deployment tools for decision support [14], elements of evidence are being gathered to demonstrated how these tools can foster a more equitable access to care in developing countries. Further evaluation is obviously needed, and should be aimed at providing better understanding of the returns on investments, changes in healthcare outcomes, as well as socio-anthropologic aspects related to the perception of patients and health professionals.

\section{Healthcare Information Systems}

The implementation of computerized healthcare information systems is a necessity to be able to cope with the increasing complexity of care processes. In the clinical setting of US hospitals, it has been demonstrated that the usage of clinical information systems can lead to reductions of in-hospital mortality, morbidity and costs [15]. The successful implementation of such systems depends on many conditions, including technological, but mostly organizational dimensions. Given the differences in financial, technological and human context, should the countries in the South embrace different strategies to successfully deploy and sustain such information systems?

\section{Cinz@n in Mali: an Free and Open Source Hospital Information System}

Our model called Cinz@n and implemented at the hospital Mere Enfant "Luxembourg" in Mali, is based on the adaptation of the free and open-source software MediBoard [16]. Cinz@n [17] means, in vernacular Bambara language, the fence around the house which always leaves an opening through which neighbors can come and go as they please. But it also means responsibility and control since it defines the boundaries of a property.

Technically MediBoard is an application based on web technologies. The advantages of this technology are obvious: ease of deployment, scaling and use, and maturity of the features used. In terms of functionality it is a complete hospital information system. 
However, the main elements for the decision to use this solutions were the fact that it was free, and was available in French.

Key steps of the projects were: the establishment of a steering committee headed by the director of the hospital, setting up hardware and operation infrastructure (servers, wiring), training of the team conducting the project and users and the implementation phase. This implementation was done in a modular way based on priorities of the hospital: the computerization of the administrative record of the patient with a scheduling management option of appointments and the computerization of medical consultation file. The deployment of additional modules such as management of the operating rooms are underway.

The evaluation has focused on basic knowledge in computer information systems, ergonomics of Cinz@n and the users' perception of the application. All users considered that the system increases significantly data reliability. One user considered that the system had no impact on improving the quality of his work, but $84 \%$ agreed that the computer system has improved the quality of their work. Two-thirds of users considered that the system workload is compatible with their duties. All users are willing to continue the experience with the deployment of new features. They also recommend that the system must be extended to all the departments of the hospital.

\section{Lessons Learned}

The first lesson learned is that it is neither utopian nor unrealistic to implement a computerized hospital information system in a developing country, despite the lack of material and operation infrastructure. The economic argument no longer holds when there are freely available open-source tools adaptable at negligible cost by local teams prepared and competent with a dual benefit: the development of local expertise and economic potentials for small local businesses.
The fear often mentioned about the inconveniences that could arise from the use of free and open-source tools is not an argument nowadays since they provide similar functionalities and the same level of security risks as commercial products. It is reassuring to see that some are being used in healthcare institutions of affluent countries.

Also, the price of paper produced each day for medical records and the cost of losing information related to the risks of paper records are more expensive to the hospital and patients than the cost of investing in the development of an adapted computerized hospital information system. For example, the average annual cost for the purchase of paper at the Hospital "Mere Enfant" is significantly greater than the sum of the cost of adapting MediBoard to its needs and the cost of basic infrastructure (server, intranet).

The economic and material aspects should not be the cause to lose sight of the cultural and organizational ones. The latter could be a true hindrance to the deployment of the system in some cases, should we fail to pay attention to them.

Indeed, when it comes to starting a new task or implementing new infrastructure, it is very common to be confronted with problems of ego strongly linked to culture. For example, we tend to believe that any investment must be introduced by the head of department or an elder; and this is seen as a great sign of respect regardless of the field. The concept of "Elder" becomes important in Africa. They must always be the first to be served as there is saying "firstserved are best served." This passage is taken very seriously in general in the African society but particularly in Mali. Therefore, it is so easy for a project of this type to fail without any obvious reason because people, paradoxically, do not openly express such deep feelings.

Another sign of success is that the Ministry of Health of Mali has decided to scale the Cinz@n HIS to all health- care facilities in Mali. Several requests are already underway by other African countries such as Burkina Faso, Niger and Cameroon.

After evaluating our model, we can conclude that users generally seem to identify issues related to the implementation of a hospital information system. As a result, users are ahead of the directors of hospitals who are still waiting to identify most of these issues. We demonstrated that Cinz@n can be deployed in the real context of a 100-bed hospital in Mali, for an investment cost of about ten thousand euros.

\section{Capacity Building of Human Resources in e-Health and Medical Informatics}

To implement and monitor these activities whether related to tele-medicine or hospital information systems, development of local skills is an absolute necessity to ensure the maintenance and sustainability. In the case of Mali, considerable effort over several years has led to the establishment of the Center for Expertise and Research in Telemedicine and E-health in Bamako, Mali. The center's role is to develop research and training in the field of e-health in Africa, especially in French- speaking regions. This center has now acquired a certain expertise and the ability to raise competitive research funds, as illustrated by the EQUI-ResHuS project.

To date the center has trained several thousand health professionals in all categories to use basic computer tools, telemedicine tools (remote medical education, tele-consultation).

More than ten students who have completed certificate courses by elearning in the field of medical informatics have been trained by the center. This is indeed the only structure of its kind in Mali and in the region. 


\section{Discussion and Conclusions}

Evidence is mounting to demonstrate how ICT can contribute to the efficiency of the health system in developing countries. It is obvious that a lot still needs to be done in terms of technological infrastructure, but these shortcomings are not insurmountable. This is why we must continue to develop applications adapted to the technological and socio-economic contexts of developing countries. The development of qualified human resources in ICT and health shall be promoted as a priority.

In the studies we have not discussed mobile-telephony based applications. Experiments are underway throughout Africa: these are promising and have yet to be evaluated.

A special attention should be paid to the qualification of eHealth and medical informatics professionals in Africa. Indeed, it is not uncommon to see untrained individuals declaring themselves specialists with empty statements and ambitions often lacking any methodology and realism in ICT and health. This kind of behavior may jeopardize the long term future of this area. Education in this field must be structured, regulated, and provided by Universities.

As demonstrated by a study paper on the role of ICT in human resource development [18], health professionals agree about the potentials of ICT in improving their work and their own development.

\section{Acknowledgments}

This work was supported by the University Hospitals of Geneva, Switzerland, the International Institute of Development and Communication, the Canadian International Development Research Centre, and the Foundation for Children of Mali through the Children Mother Hospital "Luxembourg."

\section{References}

1. www. who.int/healthacademy/new / eHealth_EB_Res-fr.pdf.

2. Thurin JM. La formation médicale continue a-telle une influence sur la pratique médicale? [Does continuing medical education have an influence on medical practice?] Psychiatrie Française 2000;1:117-32.

3. Carriere MF, Harvey D. Etat de la formation médicale continue à distance en Amérique du nord. [Status of distance continuing medical education in NorthAmerica.] Revue du conseil Québécois de la formation à distance $2003 ;: 51-72$.

4. Kemp LJ. Learning about Teamwork in an online study environment. MERLOT, Journal of Online Learning and Teaching 2006;2(1):30-41.

5. Brauchli K, O’Mahony D, Banach L, Oberhozer M. iPath - a Telemedicine Platform to Support Health Providers in Low resource Settings. The journal of information Technology in Healthcare 2005;3(4): 227-35.

6. Geissbuhler A, Ly O, Lovis C, L'Haire JF. Telemedicine in Western Africa: lessons learned from a pilot project in Mali, perspectives and recommendations. AMIA Annu Symp Proc 2003:249-53.

7. Bagayoko CO, Mueller H, Geissbuhler A. Assessment of Internet-based Telemedicine in Africa (the RAFT Project ). Comput Med Imaging Graph 2006; 30(6-7):407-16

8. Geissbuhler A, Bagayoko CO, Ly O. The RAFT network: 5 years of distance continuing medical education and tele-consultations over the Internet in French-speaking Africa. Int J Med Inform
2007;76:351-6

9. RAFT website, http://raft.hcuge.ch, last visit, 20 February 2011

10. http://www.who.int/collaboratingcentres/en/

11. Bagayoko CO. Réseau de Télé-enseignement Médical: Identification des Barrières Technologiques, Organisationnelles et Humaines. [Medical e-learning network: identification of technological, organizational and human barriers.] Master d'Informatique Bio-Médicale 2005-2006, Université de Paris 5 .

12. Décret n²010-1229 du 19 octobre 2010 relatifà la télémédecine [2010 Decree from the French government on Telemedicine], http://www. legifrance.gouv.fr/

13. EQUI-ResHuS website, www.certesmali.org/ equireshus

14. Bagayoko CO, Niang M, Traoré ST, Bediang G, Naef JM, Geissbuhler A. Deploying Portable Ultrasonography with Remote Assistance for Isolated Physicians in Africa: Lessons from a Pilot Study in Mali. Stud Health Technol Inform 2010;160 (Pt 1):554-8.

15. Amarasingham R, Plantinga L, Diener-West M, Gaskin DJ, Powe NR. Clinical information technologies and inpatient outcomes. A multiple hospital study. Arch Int Med 2009;169(2):108-14.

16. Website Mediboard, www.mediboard.org

17. Bagayoko CO, Dufour JC, Chaacho S, Bouhhadou O, Fieschi M. Open Source Challenges for Hospital Information System (HIS) in developing countries: a pilot project in Mali. BMC Med Inform Decis Mak 2010 Apr 16;10:22. Available from: http:// www.biomedcentral.com/1472-6947/10/22

18. Bagayoko CO, Traore AK. Analyse du contexte des Technologies de l'Information et de la Communication dans le développement des Ressources Humaines en santé au Mali. [Context analysis of ICT for the development of human resources for health in Mali.] Etude de synthèse, décembre 2010.

Correspondence to:

Dr. Cheick Oumar Bagayoko

Centre d'Expertise et de Recherche

En Télémedecine et E-santé, CERTES

Bamako, Mali

E-mail: cob@hcuge.ch 